Philadelphia College of Osteopathic Medicine

DigitalCommons@PCOM

Otolaryngology (ENT) Resident Research

Graduate Medical Education Research

6-6-2020

\title{
Nasal Bone Fractures: Differences Amongst Sub-Specialty \\ Consultants
}

Jason E. Cohn

Philadelphia College of Osteopathic Medicine

Sammy Othman

Michael Toscano

Tom Shokri

Jason D Bloom

See next page for additional authors

Follow this and additional works at: https://digitalcommons.pcom.edu/ent_residents

Part of the Otolaryngology Commons

\section{Recommended Citation}

Cohn, Jason E.; Othman, Sammy; Toscano, Michael; Shokri, Tom; Bloom, Jason D; and Zwillenberg, Seth, "Nasal Bone Fractures: Differences Amongst Sub-Specialty Consultants" (2020). Otolaryngology (ENT) Resident Research. 62.

https://digitalcommons.pcom.edu/ent_residents/62

This Article is brought to you for free and open access by the Graduate Medical Education Research at DigitalCommons@PCOM. It has been accepted for inclusion in Otolaryngology (ENT) Resident Research by an authorized administrator of DigitalCommons@PCOM. For more information, please contact library@pcom.edu. 
Authors

Jason E. Cohn, Sammy Othman, Michael Toscano, Tom Shokri, Jason D Bloom, and Seth Zwillenberg 


\title{
Nasal Bone Fractures: Differences Amongst Sub-Specialty Consultants
}

Annals of Otology, Rhinology \& Laryngology I-9

(C) The Author(s) 2020

Article reuse guidelines:

sagepub.com/journals-permissions DOI: I0.1 I77/000348942093।562

journals.sagepub.com/home/aor

(9SAGE

\author{
Jason E. Cohn, DO' 1 , Sammy Othman, BA² ${ }^{D}$, Michael Toscano, BA ${ }^{3}$, \\ Tom Shokri, MD ${ }^{4} \mathbb{D}$, Jason D. Bloom, MD ${ }^{5,6}$, and Seth Zwillenberg, MD $^{7}$
}

\begin{abstract}
Background: Nasal fractures constitute the largest proportion of facial trauma each year, however, there is no consensus management. In this study, we investingated the role of the consultant and the functional and aesthetic outcomes of procedures performed to address nasal bone fractures.

Methods: A retrospective chart review of patients who sustained nasal bone fractures was conducted from $8 / 1 / 14$ through 1/23/18. Categorical variables were analyzed using chi-squared testing and Fisher's exact test, where appropriate, while continuous variables were compared using Mann-Whitney $U$ testing.

Results: During the study period, 136 patients met inclusion criteria for full analysis. The mean age of this cohort was $47.6 \pm 20.2$ years with the majority identifying as African-American $(53.7 \%)$ and male $(67.2 \%)$. Otolaryngologists were significantly more likely to assess pre-operative nasal obstruction (100\%) compared to plastic surgeons $(24.1 \%)(P<.001)$. Otolaryngology elected operative management $(53.3 \%)$ at a significantly higher rate than plastic surgery $(24.1 \%)(P=.005)$. Additionally, otolaryngology was significantly more likely to manage patients in an outpatient setting (91.2\%), whereas plastic surgery more commonly performed inpatient management $(57.1 \%)(P=.006)$. Plastic surgery averaged a significantly shorter amount of time from presentation to operative management $(7.3 \pm 10.7$ days $)$ compared to otolaryngology $(20 \pm 27.7)(P=.019)$. Consulting service was not associated with a need for revision surgery.

Conclusions: Consultants across subspecialties differ in the management of nasal bone trauma. A more standardized approach is warranted by all individuals involved in the care of maxillofacial trauma patients.
\end{abstract}

\section{Keywords}

nasal fracture, Miscellaneous, Facial trauma, Reconstruction, Facial Plastic and Reconstructive Surgery, Nose

\section{Introduction}

Nasal fractures constitute the largest proportion of facial trauma each year in the United States due to the fragility of both the cartilaginous and bony structures, as well as its prominence on the face, often making it the first point of impact in facial injuries. ${ }^{1-2}$ Nasal bone fractures are commonly a result of motor vehicle accidents, falls, sportsrelated trauma, and interpersonal violence..$^{2-14}$ Males are affected approximately twice as often as females, with a peak incidence occurring in the second and third decades of life. ${ }^{3,9-10,12-17}$ Common presentations include nasal deformity, swelling, epistaxis, and periorbital ecchymosis, while bony crepitus and nasal segment mobility can also be diagnostic. ${ }^{3}$ Nasal bone fractures often require reduction within 2 weeks of injury to achieve an optimum outcome. Unfortunately, a delay in diagnosis or treatment beyond this window can lead to a persistent functional and/or cosmetic deformity requiring further surgical intervention. ${ }^{18}$

There is no consensus regarding operative techniques, timing of repair, and post-operative management for nasal bone fractures in the literature. ${ }^{19}$ With the high incidence of nasal fractures and the demands for cost-effectiveness, there is a need for more research on this topic. ${ }^{15}$ In this study, we investigated the role of the consultant and the

\footnotetext{
'Department of Otolaryngology—Head and Neck Surgery, Philadelphia College of Osteopathic Medicine, Philadelphia, PA, USA

${ }^{2}$ Drexel University College of Medicine, Philadelphia, PA, USA

${ }^{3} \mathrm{New}$ York Institute of Technology College of Osteopathic Medicine, Glen Head, NY, USA

${ }^{4}$ Department of Otolaryngology-Head and Neck Surgery, Penn State Hershey Medical Center, Hershey, PA, USA

${ }^{5}$ Department of Otolaryngology-Head \& Neck Surgery, Division of Facial Plastic Surgery, University of Pennsylvania, Philadelphia, PA, USA ${ }^{6}$ Bloom Facial Plastic Surgery, Two Town Place, Bryn Mawr, PA, USA ${ }^{7}$ Department of Otolaryngology-Head and Neck Surgery, Einstein Medical Center, Philadelphia, PA, USA

Corresponding Author:

Jason E. Cohn, DO, Department of Otolaryngology—Head and Neck Surgery, Philadelphia College of Osteopathic Medicine, 4I90 City Line Avenue, Philadelphia, PA 19131, USA.

Email: jasoncoh@pcom.edu
} 
Table I. Patient Demographics Compared by Consulting Service.

\begin{tabular}{lcccr}
\hline & Plastic Surgery $(\mathrm{n}=29)$ & & Otolaryngology $(\mathrm{n}=107)$ & \\
\cline { 2 - 3 } & $\mathrm{N}(\%)$ & & $\mathrm{N}(\%)$ & P-Value \\
\hline Age (mean \pm standard deviation in years) & $47.1 \pm 23$ & & $77.7 \pm 19.6$ & .742 \\
Sex (male) & $15(51.7 \%)$ & & .039 \\
Race/Ethnicity & & & .122 \\
Caucasian & $6(20.7 \%)$ & $32(29.9 \%)$ & \\
African-American & $17(58.6 \%)$ & $56(76.7 \%)$ & \\
Hispanic & $3(10.3 \%)$ & & $17(15.9 \%)$ & \\
Asian & $3(10.3 \%)$ & $2(1.9 \%)$ & \\
\hline
\end{tabular}

functional and aesthetic outcomes of procedures performed to address nasal bone fractures. We assessed whether consulting otolaryngologists differ from plastic surgeons in their evaluation and treatment of a nasal trauma patient, and hypothesize that otolaryngologists may be more likely to assess functional nasal parameters.

\section{Methods}

Following IRB approval, a retrospective chart review was conducted through the Einstein Healthcare Network (Philadelphia, PA) from 8/1/14 through 1/23/18. Patients $>18$ years of age who sustained an acute, isolated nasal bone fracture confirmed on computed tomography (CT) scan whom were evaluated by a consultant with at least 1 follow-up visit were included. Patients were excluded if they were $<18$ years of age, sustained other maxillofacial fracture(s), sustained a concomitant septal fracture, and if no consultation was performed by a maxillofacial trauma service. Furthermore, patients who were evaluated by the oral maxillofacial surgery (OMFS) service were excluded due an unavailability in follow-up documentation.

Patients with nasal bone fractures were identified using ICD-10 and CPT codes, using a sample size of convenience. Information abstracted included patient age, sex, and race/ ethnicity. Furthermore, the consulting team, fracture management, and if surgically managed, the type of surgery, setting and time interval to treatment were recorded. Practice patterns of the two consulting teams (otolaryngology and plastic surgery) were compared to determine if they differed in the evaluation (nasal obstruction, cosmetic deformity) and operative management (type of surgery, time interval to treatment, splint usage, and revision surgery) of patients. Types of surgeries included closed reduction, open reduction, and septorhinoplasty.

Descriptive statistics were used to present incidence of variables. Categorical variables were analyzed using chisquared testing and Fisher's exact test, while continuous variables were compared using Mann-Whitney U testing. Statistical significance was set as $P \leq .05$. Statistical analysis was performed using IBM SPSS ${ }^{\circledR}$ (Armonk, NY).

\section{Results}

During the study period, a total of 690 patients incurred an acute, isolated nasal bone fracture. The average age of this cohort was $45.6 \pm 18.4$ years, with the majority being African-American (64.6\%) and male (69.1\%). A formal consultation was conducted for 176 patients $(25.5 \%)-107$ with otolaryngology $(60.8 \%), 29$ with plastic surgery (16.5\%), and 40 with OMFS (22.7\%; excluded from analysis). As a result of the study parameters and inclusion criteria, 136 patients were identified as appropriate for analysis - 107 patients with otolaryngology $(78.7 \%)$ and 29 patients with plastic surgery $(21.3 \%)$. The mean age of this sub-cohort was $47.6 \pm 20.2$ years with the majority of patients identifying as African-American (53.7\%) and male (67.6\%). Neither age nor race/ethnicity differed by consulting service, however, otolaryngology evaluated a greater proportion of male patients (72\%) compared to plastic surgery $(51.7 \%)(P=.039)$ (Table 1$)$.

Upon presentation, the majority of patients had a degree of nasal obstruction (83.8\%) and cosmetic deformity (97.1\%) documented by the consulting physician. Nearly half of the patients underwent operative management (47.1\%), with a mean of $18.7 \pm 26.4$ days from the time of presentation to operative intervention. Otolaryngology operated on $57(53.3 \%)$ patients, which included 44 (77.2\%) closed reduction, $11(19.3 \%)$ open reduction, and two (3.5\%) septorhinoplasty. Seven patients (12.3\%) required revision surgery, which included five $(71.4 \%)$ secondary open reduction and two (28.6\%) secondary septorhinoplasty. In contrast, plastic surgery operated on seven (24.1\%) patients, which included six (85.7\%) closed reduction and one (14.3\%) septorhinoplasty. No patients managed by plastic surgery required revision surgery.

Otolaryngologists were significantly more likely to assess pre-operative nasal obstruction (100\%) compared to plastic surgeons $(24.1 \%)(P<.001)$. Both services assessed cosmetic deformity to a similar extent. Otolaryngology elected operative management $(53.3 \%)$ at a significantly higher rate than plastic surgery $(24.1 \%)(P=.005)$. Additionally, otolaryngologists were more likely to manage 
Table 2. Practice Patterns by Consulting Service.

\begin{tabular}{|c|c|c|c|}
\hline & Plastic Surgery $(n=29)$ & Otolaryngology $(n=107)$ & \\
\hline & $\mathrm{N}(\%)$ & $\mathrm{N}(\%)$ & $P$-Value \\
\hline \multicolumn{4}{|l|}{ Management characteristics } \\
\hline Assessed nasal obstruction & 7 (24.1\%) & 107 (100\%) & $<.001$ \\
\hline Assessed cosmetic deformity & $28(96.6 \%)$ & $104(99 \%)$ & .326 \\
\hline Operative Management & $7(24.1 \%)$ & $57(53.3 \%)$ & .005 \\
\hline Management setting & & & .006 \\
\hline Outpatient & $3(42.9 \%)$ & 52 (91.2\%) & \\
\hline Inpatient & $4(57.1 \%)$ & $5(8.8 \%)$ & \\
\hline $\begin{array}{l}\text { Time from Presentation to Surgery (mean/ } \\
\text { standard deviation in days) }\end{array}$ & $7.3 \pm 10.7$ & $20 \pm 27.7$ & .019 \\
\hline
\end{tabular}

Table 3. Demographics and Characteristics of Patients Receiving a Nasal Splint.

\begin{tabular}{|c|c|c|c|}
\hline & Received Splint $(n=47)$ & No Splint $(n=17)$ & \\
\hline & $\mathrm{N}(\%)$ & $\mathrm{N}(\%)$ & $P$-Value \\
\hline Age (mean \pm standard deviation in years) & $39.6 \pm 16.6$ & $40.1 \pm 16.1$ & .885 \\
\hline Sex (male) & $32(68.1 \%)$ & $10(58.8 \%)$ & .491 \\
\hline Race/Ethnicity & & & .578 \\
\hline Caucasian & $10(21.3 \%)$ & $4(23.5 \%)$ & \\
\hline African-American & 29 (61.7\%) & $8(47.1 \%)$ & \\
\hline Hispanic & $5(10.6 \%)$ & $4(23.5 \%)$ & \\
\hline Asian & $3(6.4 \%)$ & I (5.9\%) & \\
\hline Consultant type & & & $<.001$ \\
\hline Plastic surgery & I (2.I\%) & $6(35.3 \%)$ & \\
\hline Otolaryngology & $46(97.9 \%)$ & II (64.7\%) & \\
\hline \multicolumn{4}{|l|}{ Management Characteristics } \\
\hline Assessed nasal obstruction & $46(97.9 \%)$ & $13(76.5 \%)$ & .005 \\
\hline Nasal obstruction present & $40(87 \%)$ & $10(76.9 \%)$ & .398 \\
\hline Improved nasal obstruction & $39(90.7 \%)$ & $10(76.9 \%)$ & .335 \\
\hline Assessed cosmetic deformity & $47(100 \%)$ & 15 (100\%) & 1.00 \\
\hline Cosmetic deformity present & $0(0 \%)$ & $2(11.8 \%)$ & .067 \\
\hline Improved cosmetic appearance & $44(95.7 \%)$ & 14 (82.4\%) & .117 \\
\hline Management setting & & & .048 \\
\hline Outpatient & 43 (91.5\%) & $12(70.6 \%)$ & \\
\hline Inpatient & $4(8.5 \%)$ & $5(29.4 \%)$ & \\
\hline $\begin{array}{l}\text { Time interval from presentation to surgery } \\
\text { (mean/standard deviation in days) }\end{array}$ & $22.4 \pm 29.9$ & $8.4 \pm 7.9$ & .012 \\
\hline
\end{tabular}

patients surgically in an outpatient setting (91.2\%), whereas plastic surgery more commonly performed inpatient management $(57.1 \%)(P=.006)$. Finally, plastic surgery averaged a significantly shorter amount of time from presentation to operative management $(7.3 \pm 10.7$ days $)$ compared to otolaryngology $(20 \pm 27.7)(P=.019)$ (Table 2$)$.

Of the 64 patients who underwent operative management, 73.4\% received a splint. No demographic variables were associated with splint usage $(P>.05$, for all). Otolaryngologists were significantly more likely to use a splint $(97.9 \%)$ after operative intervention compared to plastic surgeons $(2.1 \%)(P<.001)$. Additionally, patients who received a splint were significantly more likely to be evaluated for nasal obstruction on the initial examination (97.9\%) compared to those who did not (76.5\%) $(P=.005)$ (Table 3).

Most patients managed with an operative intervention had some form of nasal obstruction (78.1\%) and cosmetic deformity (81.3\%). Following surgery, most patients experienced a reduction in nasal obstruction (76.6\%) and an improved cosmetic appearance $(90.1 \%)$. These factors were not associated with splint usage $(P>.05$, for all). However, 
Table 4. Demographics and Characteristics of Patients Requiring Revision Surgery.

\begin{tabular}{|c|c|c|c|}
\hline & Revision Surgery $(n=7)$ & No Revision $(n=57)$ & \\
\hline & $\mathrm{N}(\%)$ & $\mathrm{N}(\%)$ & $P$-Value \\
\hline Age (mean \pm standard deviation in years) & $54.7 \pm 9.1$ & $37.8 \pm 16.1$ & .004 \\
\hline Sex (male) & $6(85.7 \%)$ & $36(63.2 \%)$ & .236 \\
\hline Race/Ethnicity & & & .813 \\
\hline Caucasian & $\mathrm{I}(\mathrm{I} 4.3 \%)$ & $13(22.8 \%)$ & \\
\hline African-American & $5(7 \mathrm{I} .4 \%)$ & $32(56.1 \%)$ & \\
\hline Hispanic & I (I4.3\%) & $8(14 \%)$ & \\
\hline Asian & $0(0 \%)$ & $4(7 \%)$ & \\
\hline Consultant type & & & 1.00 \\
\hline Plastic surgery & $0(0 \%)$ & $7(12.3 \%)$ & \\
\hline Otolaryngology & $7(100 \%)$ & $50(87.7 \%)$ & \\
\hline \multicolumn{4}{|l|}{ Management characteristics } \\
\hline Assessed nasal obstruction & $7(100 \%)$ & $52(91.2 \%)$ & 1.00 \\
\hline Nasal obstruction present & $7(100 \%)$ & $43(86 \%)$ & .232 \\
\hline Improved nasal obstruction & $4(57.1 \%)$ & $43(75.4 \%)$ & .370 \\
\hline Assessed cosmetic deformity & I (I4.3\%) & 48 (98\%) & $<.001$ \\
\hline Cosmetic deformity present & 7 (100\%) & 55 (100\%) & 1.00 \\
\hline Improved cosmetic appearance & $2(28.6 \%)$ & $56(100 \%)$ & $<.001$ \\
\hline Management setting & & & .580 \\
\hline Outpatient & $7(100 \%)$ & $48(84.2 \%)$ & \\
\hline Inpatient & $0(0 \%)$ & $9(15.8 \%)$ & \\
\hline $\begin{array}{l}\text { Time interval from presentation to surgery } \\
\text { (mean/standard deviation in days) }\end{array}$ & $15.4 \pm 4.9$ & $19.1 \pm 28.1$ & .060 \\
\hline
\end{tabular}

splint usage was associated with outpatient management $(91.5 \%, P=.048)$ and a significantly longer time interval from presentation to surgery (22.4 days) compared to those who did not receive a splint (8.4 days) $(P=.012)$ (Table 3$)$.

Patients requiring revision surgery demonstrated a more advanced age (54.7 years) compared to those who did not (37.8 years) $(P=.004)$. Sex and race/ethnicity were not associated with revision surgery $(P>.05$, for both). Consulting service was also not associated with a need for revision surgery. However, patients assessed for cosmetic deformity prior to surgical intervention were significantly less likely to require revision surgery $(2 \%)$, compared to those not assessed for a deformity $(14.3 \%)(P<.001)$. Additionally, all patients $(100 \%)$ with improved post-operative cosmetic appearance did not require revision surgery. However, of the patients who required revision surgery, $28.6 \%$ of patients did not experience cosmetic improvement $(P<.001)$ (Table 4$)$. Management setting (inpatient versus outpatient) and time interval from presentation to treatment were not shown to predict revision surgery.

\section{Discussion}

Nasal bone fractures are often overlooked and undertreated often leading to undesirable sequelae. The diagnosis and treatment of delay operative management on an outpatient basis compared to plastic surgery colleagues.
Nasal bone fractures are the third most common fracture of the human skeleton, comprising 39\% of patients with maxillofacial trauma. ${ }^{15,20-22}$ Many studies clearly define the importance of a thorough history and physical exam when approaching patients with a possible nasal frac-

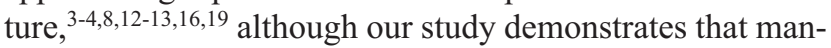
agement may differ by sub-specialty, as otolaryngologists are significantly more likely to assess nasal obstruction and utilize splints after surgical intervention. In addition, demographic data, patient age, chief complaint, history of injury, direction of blow, and differentiating acute versus chronic deformity/obstruction may all play a role in patient management. ${ }^{4,8,13,15,19}$ Higuera et al. went on to delineate the signs and symptoms of nasal fractures, which include cerebrospinal fluid rhinorrhea, epistaxis, periorbital ecchymosis, tenderness to palpation and a palpable deformity. ${ }^{8}$ An external evaluation, including palpation to detect step-offs and areas of tenderness as well as observation of nasal deviation, should be performed on all patients presenting with nasal trauma. This should be followed by an internal examination with proper lighting, a nasal speculum and suction. ${ }^{6,8,16,19}$ A rigid or flexible endoscope can facilitate this examination, but is not a necessity. The most indicative sign of fracture is a tender, palpable or visible deformity. ${ }^{8}$

The demographics of this study cohort were somewhat consistent with the existing literature. ${ }^{9-10,13,15-17,23-24}$ Most of the patients were male and otolaryngologists evaluated a 


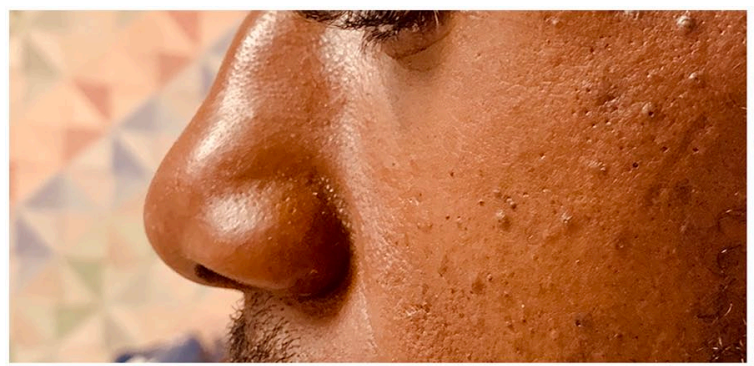

A

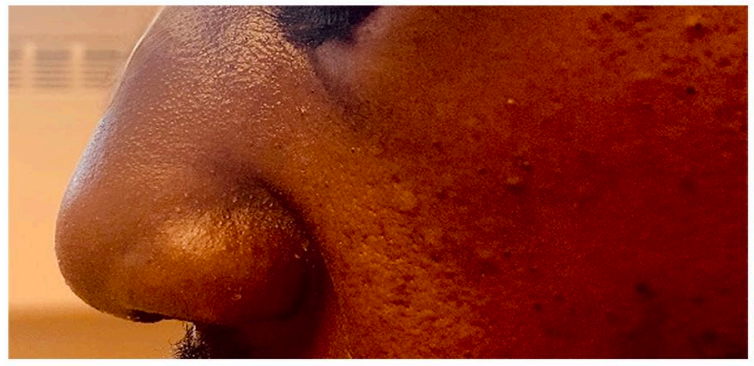

C

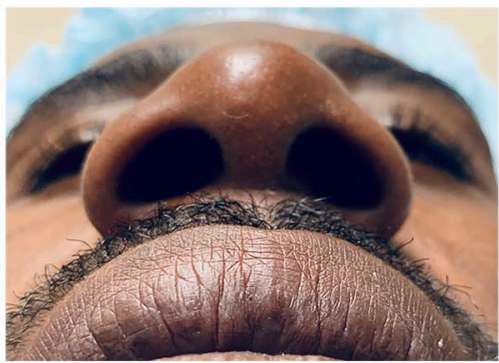

B

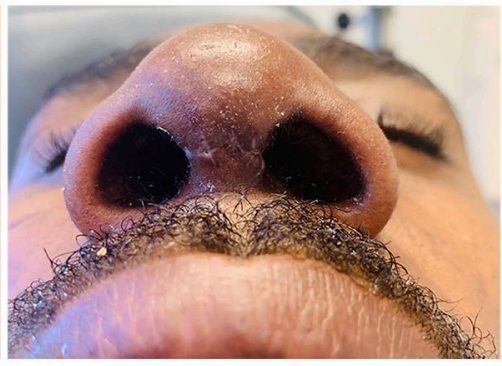

$\mathrm{D}$

Figure I. (A) 28-year-old male who underwent open septorhinoplasty following nasal trauma. Note significant dorsal hump (B) and poor columellar height on base view. (C) Following open septorhinoplasty, the patient exhibited improved dorsal contour (D) and columellar height.

Note. These changes can be more subtle in an African-American patient with thick skin, as seen in these photos.

greater proportion $(72 \%)$ compared to plastic surgeons $(51.7 \%)$, which we believe is incidental. Although the age profile of our cohort was slightly more advanced (mean $47.6 \pm 20.2$ years) compared to previous studies, patients undergoing operative management were younger (mean $39.7 \pm 6.2$ years). The majority of patients were identified as African-American, which varies in the literature depending on study location. Our institution draws patients from an urban, underserved neighborhood with a higher proportion of minority populations. While treating this patient population, it is important to remember that AfricanAmerican features can be markedly different from other ethnic groups. African-Americans, on average, have wider and shorter nose than a typical European American and have an acute columella and nasolabial angle. They also tend to have thicker nasal skin with a thick fibro-fatty sublayer and a bulbous fatty nasal tip, weak lower lateral cartilage, and large nostrils in the vertical and horizontal dimensions. This features can be appreciated in Figure 1, which displays an African-American patient from our series who underwent open septorhinoplasty following nasal trauma ${ }^{25}$ (Figure 1).

Most practitioners treating facial trauma will undoubtedly encounter nasal bone trauma. ${ }^{6,26}$ In our series, both the otolaryngology and plastic surgery services performed consultations. They evaluated patients for cosmetic deformity in a similar manner, however, otolaryngologists were significantly more likely to assess nasal obstruction. This distinction led to differences in patient management. Most of the patients had some form of nasal obstruction (78.1\%) and cosmetic deformity $(81.3 \%)$ prior to their procedure. Following surgery, most patients experienced a reduction in nasal obstruction (76.6\%) and an improved cosmetic appearance (90.1\%). Additionally, all patients with improved post-operative cosmetic appearance did not require revision surgery.

A systematic review conducted by Hwang et al. demonstrated an overall nasal deformity rate of $10.4 \%,{ }^{27}$ while Fernandes observed 100\% cosmetic deformity and 73\% nasal obstruction in his cohort. ${ }^{7}$ Two otolaryngologists, Crowther and O'Donoghue, surveyed nasal fracture patients following reduction. In this series, $72 \%$ of patients reported that their nose appeared similar to what it was before injury while $28 \%$ felt they had a residual external deformity. In addition, $36 \%$ reported nasal obstruction. However, $>50 \%$ did not feel they required revision surgery. ${ }^{23} \mathrm{~A}$ study by another otolaryngologist Hung reported that $13 \%$ of patients were dissatisfied with their nasal deformity, $11 \%$ with their aesthetic appearance and $21 \%$ with their nasal patency following reduction. In addition, 29\% requested revision surgery ${ }^{9}$ which mirrored a similar study. ${ }^{21}$ Although, others have reported higher satisfaction rates. ${ }^{21-22,28}$ In one review of 13 studies, patients were happy following closed reduction with an average satisfaction rate of $79 \%$, while surgeon satisfaction only averaged $37 \%{ }^{29}$ A study by Yoon et al. observed no differences in post-reduction satisfaction between patients who had and did not have rhinoplasty. 
Although, rhinoplasty patients were more likely to want a secondary procedure. ${ }^{30}$

Treatment of nasal bone trauma is not always required. If deformity or nasal obstruction is not present, observation alone is adequate. ${ }^{31}$ In our cohort, nearly half of the patients underwent operative management. A larger proportion of these patients were managed surgically by the otolaryngology service $(53.3 \%)$ compared to plastic surgery $(24.1 \%)$. Both services initially treated patients with closed reduction $(>70 \%)$, while open reduction and septorhinoplasty were utilized less often or in revision cases. This is similar to rates reported in the literature. ${ }^{23,26}$ There are two principal methods in treating nasal bone fractures - closed reduction or open reduction. ${ }^{14,21,28,30}$ Some of the advantages of closed reduction are that its simple, safe, fast, easy to perform, cost-effective and has minimal associated morbidity., ${ }^{4,20,28}$ In previous studies, closed reduction alone had a success rate of $89 \%$ to $94.5 \%{ }^{16,26}$ Open reduction or septorhinoplasty has classically been reserved for closed reduction failures. ${ }^{4,23,26}$ Factors associated with undergoing a subsequent septorhinoplasty include young age, female gender, living in an urban setting and in the Western part of the United States, history of anxiety and a history of a preexisting nasal obstruction or defect. ${ }^{32}$ Many recommend waiting 3 to 12 months for secondary repair. ${ }^{4,12-13,24,33-34}$ However, others have advocated for concomitant septorhinoplasty with closed reduction to achieve a better cosmetic result. ${ }^{22,24,31,33}$

In this study, otolaryngologists were more likely to manage patients at a later date in an outpatient setting, whereas plastic surgery intervened earlier in an inpatient setting. Nasal bone fractures can be repaired within the first few hours of injury before swelling ensues. However, this is rare and most patients are managed 2 to 14 days following trauma to allow for swelling to subside. ${ }^{8,12,15-16,21}$ It has been suggested that repair within the first 14 days of injury will decrease the likelihood of a patient needing a septorhinoplasty. ${ }^{26}$ However, others have identified that delaying repair 2 to 5 weeks is acceptable. ${ }^{34}$ As stated above, most patients in this cohort were successfully managed with closed reduction with very few patients requiring secondary open reduction or septorhinoplasty. Although otolaryngologists managed patients 20 days post-injury on average in this study, the large standard deviation (27.7) indicates there were outliers. A similar study reported that patients presented 15.6 (range 4-30) days post-injury on average. ${ }^{7}$ The best explanation for this at a Level 1 trauma center are other serious injuries precluding the patients from early operative repair. ${ }^{26}$ After all life-threatening and major organ injuries are dealt with, a secondary evaluation can be performed. ${ }^{6}$

In this study, $73.4 \%$ of patients who underwent surgical intervention received a splint. Otolaryngologists were more likely to use a splint $(97.9 \%)$ compared to plastic surgeons $(2.1 \%)$. This is likely a product of surgeon preference and post-graduate training which is based on anecdotal tradition rather than randomized controlled studies. ${ }^{20,35}$ It is wellreported in the literature that many surgeons use splints after reduction regardless of specialty. ${ }^{6,15-16}$ Splints support and protect the nasal bones and cartilages, helps with the adherence of the skin to the underlying framework, aid in elimination of dead space and helps maintain reduction. ${ }^{6,8}$ However, the benefit of splints is still debated, given their controversial stabilizing effect in complex or severely displaced fractures, patient discomfort, time-consuming application, cost, and potential for complications. In one study, splints were only used in $18.19 \%$ of repaired nasal bone fractures. They advocated splint use only for severely comminuted fractures managed by closed reduction. ${ }^{20}$ Commonly used splints include aluminum Denver splints (Shippert Medical Technologies, Inc., Centennial, Colo.), Aquaplast (WFR/Aquaplast Corp; Avondale, Pa.), plaster of Paris, amongst others. ${ }^{15-16}$ Our patients typically followed-up 1-week post-procedure, which is consistent with the literature for splint removal. ${ }^{16,20,34}$ However, others recommend a more extensive follow-up that can extend 3 to 12 months out. ${ }^{7,15,17,21,36}$

Nasal fractures are sometimes misperceived to be insignificant, however they often need to be reevaluated, ${ }^{11,16,23}$ as $9 \%$ to $62 \%$ of all closed reductions or observations can result in revision surgery to treat sequelae such as obstruction or deformity correction. $4,7-9,14,19,22-23,26,28-29,34,37-38$ More notably, there are even higher dissatisfaction rates amongst surgeons treating nasal fractures. ${ }^{22,29}$ In one study, 14 patients $(15.6 \%)$ reported post-operative deformity. Of these, $71.4 \%$ were classified as functional and cosmetic, whereas the remaining $28.6 \%$ had only a functional deformity. ${ }^{16}$ It has recently been shown that a preexisting nasal obstruction or defect was associated with higher rates of revision septorhinoplasty. ${ }^{31,34}$ Within our cohort, $12 \%$ of patients managed by the otolaryngology service required revision surgery, which included secondary open reduction and septorhinoplasty. In contrast, no patients managed by plastic surgery required revision surgery. One explanation for this is that otolaryngologists operated on $>50 \%$ patients they evaluated, while plastic surgery operated on $<25 \%$. Additionally, all otolaryngologists evaluated for nasal obstruction, both pre- and post-operatively, which could have uncovered more signs and symptoms for operative repair. Finally, otolaryngology was more likely to manage patients in an outpatient setting, therefore there may have been a greater potential for follow-up to determine whether revision surgery was indicated. Nonetheless, revision rates were not found to differ significantly between the two managing teams. Our series suggests a more advanced age and persistent cosmetic deformity may predict the need for revision surgery. In the elderly, the keystone area of the nasal bone, which is a clinically important structure for maintaining the stability of the dorsum of the nose, becomes weak due to the decrease in the volume of septal cartilage by 
ossification. This may be one explanation for these patients requiring revision surgery. ${ }^{39}$

Although our study could not properly evaluate OMFS, recommend approach and guidelines have been delineated in previous literature. ${ }^{40-42}$ Management begins with accurate diagnosis through both radiography and physical examination, as thorough evaluation for visible deformity and obstruction is critical to guiding the next steps, dictates management approach as well as timing Severe deformity and obstruction most often require more immediate, and likely surgical, intervention, as these may compromise patient airway or represent greater pathology. Other findings may benefit from a delayed approach in order to assess the full extent of pathology, such as undetected deformity and late-forming edema. The closed approach is reserved for more acute, less severe injury, given that it is performed in a timely manner (ie, 10 days after injury or sooner), with generally good outcomes. Patients who require surgery will be those who have severe deformity in which closed reduction would be inadequate, requiring open reduction and/or complete septorhinoplasty. Regardless, splinting is recommended for both approaches in order to maintain patency, as is more acute treatment ( $10>$ days).

The results of this study should be interpreted in the background of certain limitations. This was a retrospective, single-center experience. Plastic surgeons failing to evaluate nasal obstruction is likely a result of the failure to document a nasal examination. An explanation for this is that most patients evaluated by the plastic surgery service were initially seen by general surgery residents. However, these patients were later evaluated in the outpatient setting by an attending physician (two board-certified plastic surgeons in the practice). All otolaryngology consultations at least documented nasal obstruction on anterior rhinoscopy + / nasal endoscopy. Patients following up at the otolaryngology outpatient office were seen by resident physicians, under the supervision of two board-certified, general otolaryngologists. Meanwhile, some patients in this study were only evaluated by the emergency medicine provider as an inpatient and were only seen by the consultant as an outpatient, which can be attributed to common curbside consults or over the phone discussions with consultants. Previous research has demonstrated that not all patients with nasal trauma require a referral to a specialist. It has been shown that patients can successfully triage themselves and decide if they need outpatient follow-up with a specialist when provided with appropriate information. ${ }^{18}$ Although, nasal fracture patients are known to have poor follow-up. ${ }^{23}$

In order to standardize the results, we chose to only evaluate patients with isolated nasal bone fractures confirmed by CT scan. This unfortunately limited our sample size because there were other individuals diagnosed by physical examination and/or plain film (ie, x-ray). Patients sustaining septal fractures were also initially included, but were then excluded because many of them subsequently underwent septoplasty which made the results more heterogeneous and difficult to analyze. This decision also limited our sample size. In this cohort, patients were more commonly evaluated by the otolaryngology team. This difference is a product of the maxillofacial call schedule at our institution-2 weeks/month otolaryngology, 1 week/month plastic surgery, and 1 week/ month OMFS - which may cofound follow-up times and approaches. One potential cause of the difference in time to treatment is that the plastic surgery service is covered by inhouse general surgery residents at all times, while otolaryngology residents are not inhouse while on call, causing potential delays in follow-up and as well as possibly conferring decreased patient admission due to non-urgent evaluation. As mentioned above, informal curbside consults were frequent, particularly within otolaryngology, which may also delay outpatient follow-up, formal consultation, and possibly cause decreased inpatient admission. Anecdotally, plastic surgeons operate less at our institution due to less operating room availability which may explain the smaller cohort with this group. Finally, the results of this study may be skewed due to the fact that OMFS consultations were excluded because follow-up documentation was unavailable. The study's external validity may be limited, as these are all listed factors specific to our institution, and thus different institutions with different protocols and/or patient populations may uncover different trends. Our future goals would be to design a prospective study which utilizes a more standardized consultation form to correct for heterogenous results amongst consultation providers. Another additional measure would be to include one of the more established diagnostic and therapeutic algorithms. Finally, patient satisfaction with each procedure should be evaluated more objectively with a validated grading scale or questionnaire.

\section{Conclusions}

Nasal bone fractures are often overlooked and undertreated often leading to undesirable sequelae. The diagnosis and treatment of nasal bone fractures can differ in many ways depending on the provider(s) involved. Otolaryngologists appear more likely to assess nasal obstruction, utilize splints after surgical intervention, and delay operative management on an outpatient basis compared to plastic surgery colleagues. Despite these findings, the decision to perform certain procedures and techniques will largely depend on the patient's needs, their anatomy and clinical presentation as well as the surgeon's preferences. As a result, a more standardized approach to certain patient types and scenarios is warranted by all individuals involved in the care of maxillofacial trauma patients. 


\section{Declaration of Conflicting Interests}

The author(s) declared no potential conflicts of interest with respect to the research, authorship, and/or publication of this article.

\section{Funding}

The author(s) received no financial support for the research, authorship, and/or publication of this article.

\section{ORCID iDs}

Jason E. Cohn iD https://orcid.org/0000-0001-5132-9832

Sammy Othman iD https://orcid.org/0000-0002-8814-1048

Tom Shokri (iD) https://orcid.org/0000-0002-1123-4385

\section{References}

1. Kim K, Ibrahim AM, Koolen PG, Lee BT, Lin SJ. Trends in facial fracture treatment using the American College of Surgeons National Surgical Quality Improvement Program Database. Plast Reconstr Surg. 2014;133(3):627-638.

2. Allareddy V, Allareddy V, Nalliah RP. Epidemiology of facial fracture injuries. J Oral Maxillofac Surg. 2011;69(1): 2613-2618.

3. Atighechi S, Karimi G. Serial nasal bone reduction: a new approach to the management of nasal bone fracture. $J$ Craniofac Surg. 2009;20(1):49-52.

4. Mondin V, Rinaldo A, Ferlito A. Management of nasal bone fractures. Am J Otolaryngol. 2005;26(3):181-185.

5. Hogg NJ, Stewart TC, Armstrong JE, Girotti MJ. Epidemiology of maxillofacial injuries at trauma hospitals in Ontario, Canada, between 1992 and 1997. J Trauma. 2000;49(3):425-432.

6. Fattahi T, Salman S. Management of nasal fractures. Atlas Oral Maxillofac Surg Clin North Am. 2019;27(2):93-98.

7. Fernandes SV. Nasal fractures: the taming of the shrewd. Laryngoscope. 2004;114(3):587-592.

8. Higuera S, Lee EI, Cole P, Hollier LH, Stal S. Nasal trauma and the deviated nose. Plast Reconstr Surg. 2007;120(7 Suppl 2):64S-75S

9. Hung T, Chang W, Vlantis AC, et al. Patient satisfaction after closed reduction of nasal fractures. Arch Facial Plast Surg. 2007;9(1):40-43.

10. Hwang K, You SH, Kim SG, Lee SI. Analysis of nasal bone fractures; a six-year study of 503 patients. J Craniofac Surg. 2006;17(2):261-264.

11. James JG, Izam AS, Nabil S, Rahman NA, Ramli R. Closed and open reduction of nasal fractures. J Craniofac Surg. 2020;31(1):e22-e26.

12. Karagama YG, Newton JR, Clayton MGG. Are nasal fractures being referred appropriately from the accident and emergency department to ENT? Injury. 2004;35(10): 968-971.

13. Lu GN, Humphrey CD, Kriet JD. Correction of nasal fractures. Facial Plast Surg Clin North Am. 2017;25(4): 537-546.

14. Murray JA. Management of septal deviation with nasal fractures. Facial Plast Surg. 1989;6(2):88-94.
15. Das TA, Aslam AS, Mangalath U, et al. Evaluation of treatment outcome following closed reduction of nasal bone fractures. J Contemp Dent Pract. 2018;19(10):1174-1180.

16. Farber SJ, Nguyen DC, Parikh RP, Jang JL, Woo AS. Improving Results in closed nasal reduction: a protocol for reducing secondary deformity. Plast Reconstr Surg. 2017;139(1):51-59.

17. Park HK, Lee JY, Song JM, Kim TS, Shin SH. The retrospective study of closed reduction of nasal bone fracture. Maxillofac Plast Reconstr Surg. 2014;36(6):266-272.

18. Baring DE, Bowyer DJ, Adamson R. Patient self-assessment of nasal fractures and self-referral to an ear, nose, and throat department: a prospective study. Otolaryngol Head Neck Surg. 2012;146(6):913-917.

19. Rohrich RJ, Adams J. Nasal fracture management: minimizing secondary nasal deformities. Plast Reconstr Surg. 2000;106(2):266-273.

20. Schoinohoriti O, Igoumenakis D, Rallis G. Fractures of the Nasal bones: is external splinting really warranted? $J$ Craniofac Surg. 2017;28(8):e760-e763.

21. Yilmaz MS, Guven M, Varli AF. Nasal fractures: is closed reduction satisfying? J Craniofac Surg. 2013;24(1):e36-e38.

22. Reilly MJ, Davison SP. Open vs closed approach to the nasal pyramid for fracture reduction. Arch Facial Plast Surg. 2007;9(2):82-86.

23. Crowther JA, O'Donoghue GM. The broken nose: does familiarity breed neglect? Ann R Coll Surg Engl. 1987;69(6): 259-260.

24. Kim JH, Lee JW, Park CH. Cosmetic rhinoseptoplasty in acute nasal bone fracture. Otolaryngol Head Neck Surg. 2013;149(2):212-218.

25. Slupchynskyj O, Gieniusz M. Rhinoplasty for African American patients: a retrospective review of 75 cases. Arch Facial Plast Surg. 2008;10(4):232-236.

26. Fattahi T, Steinberg B, Fernandes R, Mohan M, Reitter E. Repair of nasal complex fractures and the need for secondary septo-rhinoplasty. J Oral Maxillofac Surg. 2006;64(12): 1785-1789.

27. Hwang K, Yeom SH, Hwang SH. Complications of nasal bone fractures. J Craniofac Surg. 2017;28(3):803-805.

28. Ondik MP, Lipinski L, Dezfoli S, Fedok FG. The treatment of nasal fractures. Arch Facial Plast Surg. 2009;11(5):296.

29. Staffel JG. Optimizing treatment of nasal fractures. Laryngoscope. 2002;112(10):1709-1719.

30. Yoon T, Kim Y. Postoperative Satisfaction in nasal bone fracture patients who had rhinoplasty. 2016;27(7):1707-1710.

31. Hoffmann JF. An algorithm for the initial management of nasal trauma. Facial Plast Surg. 2015;31(3):183-193.

32. Li K, Moubayed SP, Spataro E, Most SP. Risk factors for corrective septorhinoplasty associated with initial treatment of isolated nasal fracture. JAMA Facial Plast Surg. 2018;20(6):460-467.

33. Kim J, Jung HJ, Shim WS. Corrective septorhinoplasty in acute nasal bone fractures. Clin Exp Otorhinolaryngol. 2018;11(1):46-51.

34. Wang W, Lee T, Kohlert S, Kadakia S, Ducic Y. Nasal fractures: the role of primary reduction and secondary revision. Facial Plast Surg. 2019;35(6):590-601. 
35. Drezner DA. Thermoplastic splint for use after nasal fracture. Otolaryngol Head Neck Surg. 1994;111(1):146-147.

36. Verwoerd CD. Present day treatment of nasal fractures: closed versus open reduction. Facial Plast Surg. 1992;8(4):220-223.

37. Terry H, Waitsz C, Vlantis AC, Tong MCF, Van Hasselt CA. Patient satisfaction after closed reduction of nasal fractures. Arch Facial Plast Surg. 2007;9(1):40-43.

38. Waldron J, Mitchell DB, Ford G. Reduction of fractured nasal bones; local versus general anaesthesia. Clin Otolaryngol. 1989;14(4):357-359.

39. Kim JH, Jung DJ, Kim HS, Kim CH, Kim TY. Analysis of the development of the nasal septum and measurement of the harvestable septal cartilage in Koreans using three-dimensional facial bone computed tomography scanning. Arch Plast Surg. 2014;41(2):163-170.

40. Ziccardi VB, Braidy H. Management of nasal fractures. Oral Maxillofac Surg Clin North Am. 2009;21(2):203-208, vi.

41. Fattahi T, Steinberg B, Fernandes R, Mohan M, Reitter E. Repair of nasal complex fractures and the need for secondary septo-rhinoplasty. J Oral Maxillofac Surg. 2006;64(12): 1785-1789.

42. Haug RH, Prather JL. The closed reduction of nasal fractures: an evaluation of two techniques. J Oral Maxillofac Surg. 1991;49(12):1288-1292. 